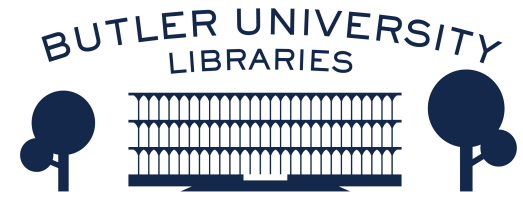

Butler University

Digital Commons @ Butler University

$6-2014$

Ejemplos de jejeo salvadoreño en Cuentos de Barro de Salarrué.

Juan Rodríguez Prieto

Follow this and additional works at: https://digitalcommons.butler.edu/facsch_papers

Part of the Modern Languages Commons 


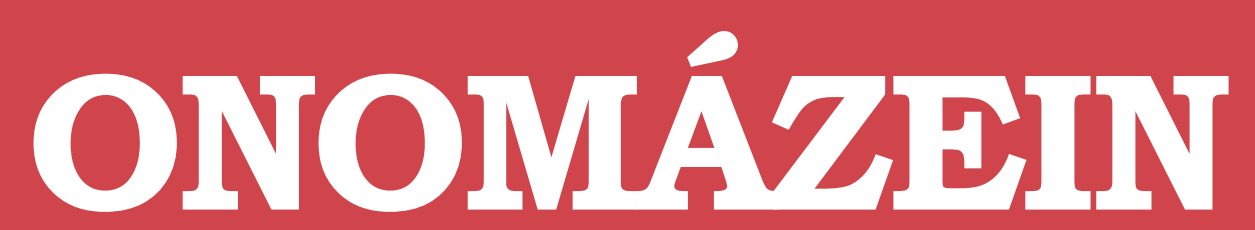

Revista semestral de lingüística, filología y traducción
PONTIFICIA UNIVERSIDAD CATÓLICA DE CHILE CATOLICA DE CHILE
FACULTAD DE LETRAS

\section{Ejemplos de jejeo salvadoreño en Cuentos de barro de Salarrué}

Examples of Salvadoran jejeo in

Salarrué's Cuentos de barro

\section{Juan Pablo Rodríguez Prieto}

Butler University

United States of America 


\section{Resumen}

Expandiendo la definición del jejeo con aspiraciones de consonantes fricativas a inicio de sílaba o palabra, se pueden definir ejemplos dialectales del tipo fuerte ['hwer.te], que anteriormente no tenían una terminología precisa que los identificara. En la obra Cuentos de barro de
Salarrué se incluyen docenas de vocablos que justifican la ampliación de la definición del jejeo, sugiriendo además la necesidad de determinar el subgrupo de consonantes fricativas que pueden sufrir dicho proceso de aspiración.

Palabras clave: jejeo; El Salvador; aspiración; Salarrué; Cuentos de barro.

\section{Abstract}

By expanding the definition of jejeo with aspirations of fricative consonants in syllable/ word initial position, dialectal examples which previously did not have a precise terminology to be identified, as fuerte ['hwer.te], can now be defined. In Salarrués Cuentos de barro there are dozens of terms that justify the expansion of the definition of jejeo, suggesting, in addittion, the need to determine the subgroup of fricative consonants that can suffer such an aspiration process.

Keywords: jejeo; El Salvador; aspiration; Salarrué; Cuentos de barro. 


\section{Introducción. ¿Qué es el jejeo?}

Se entiende por jejeo la sustitución esporádica y condicionada léxicamente del alófono [s] por [h] a principio de sílaba o de palabra, por ejemplo: cuando se pronuncia la palabra señor como jeñó, o la afirmación sí como jí. Es un rasgo lingüístico estigmatizado aunque tiene una distribución amplia en Latinoamérica, además de encontrarse en el sur de España. Lo suelen emplear hablantes con poco nivel de instrucción o pertenecientes a estratos socioeconómicos bajos, y es usado en el habla informal o descuidada. No obstante, también lo utilizan los hablantes cultos en el lenguaje informal o familiar. Según Narbona y otros (2003), este fenómeno tiene todas las características de un cambio lingüístico embrionario que no ha podido desarrollarse y que, por lo tanto, permanece restringido al habla de determinadas personas y en la producción de ciertas palabras.

El jejeo todavía no es un término ampliamente aceptado como lo es el del seseo. De hecho, se suele hacer referencia a este fenómeno como la aspiración de /s/ a inicio de palabra o de sílaba. Según Rodríguez (2008), el término de aspiración carece de todo formalismo pese a ser la opción más precisa y descriptiva. Dicho autor tampoco favorece el uso de heheo, escrito con haches, ya que esta letra no suele pronunciarse en la mayoría de las variedades del español, es decir, no se pronuncia [e.'eo]. Y de tener que elegir entre gegeo y jejeo, se justifica el uso de la versión escrita con jotas ya que ofrece una mayor consistencia ortográfica y fonética con el fenómeno en sí. De hecho, muchos lingüistas y escritores ofrecen en sus trabajos ejemplos de jejeo ortográficamente del tipo nohotros/nojotros en vez de ofrecer la palabra y su correspondiente transcripción fonética, como por ejemplo: nosotros [no.'ho.troh] (donde corresponda). Con el objetivo de obtener una mayor consistencia ortográfica que representa la pronunciación jejeísta, Rodríguez (2008) propuso el empleo de jotas en vez de ges. Por el contrario, si se escribieran los ejemplos de jejeo con la grafía G empleada en el nombre del fenómeno, se estaría incorporando una asociación alofónica de /s/ a [y] que es inexistente en este fenómeno, a saber: nogotros o magomenos.

\section{La nueva definición del fenómeno del jejeo}

En español, el proceso de la aspiración esporádica y léxicamente condicionada a inicio de palabra o de sílaba no es exclusivo del fonema /s/. Otros sonidos sufren este mismo proceso. Por esta razón, Rodríguez (2008) propuso ampliar la definición del jejeo incluyendo todas las consonantes fricativas. La nueva definición que se propuso fue la siguiente: El jejeo es la sustitución esporádica y condicionada léxicamente de las consonantes fricativas por [h] a principio de palabra o de sílaba, como en los siguientes ejemplos: ['hwis.te] ${ }^{1}$ para fuiste, [he.'ma.na] para semana, etc.

El jejeo es un fenómeno que no se aplica de manera consistente. Una palabra puede pronunciarse con jejeo en un momento dado e inmediatamente después la misma palabra se articula sin aspiración por el mismo hablante. Como muestra de esta característica se puede mencionar el estudio de Schwegler (1991) en el que un informante de la localidad de Viro-Viro en el Chocó, Colombia, dijo: Yo no lo sé ['se] no. No lo sé ['se], ni el nacimiento... Pero unas oraciones más adelante pronunció la misma forma verbal del verbo saber con jejeo: Yo no los vi nunca no; sí sé ['he] que bailaron, en base a las transcripciones ofrecidas por Schwegler (1991: 98-99). Esta inconsistencia se encuentra incluso en palabras que se pronuncian casi seguidas la una de la otra. En el mismo estudio, un hablante de Bagadó dijo lo siguiente en un momento dado: Entonces dice ['óí.he] así... donde está el alcalde... dice ['סis] así. (Schwegler, 1991: 104).

1 La semivocal palatal va a transcribirse con el símbolo fonético [j] y la semivocal labiovelar con el símbolo [w] 
El jejeo es además un fenómeno que está léxicamente condicionado, es decir, que solamente ocurre en una serie de palabras y que no aplica en absoluto a toda sílaba o palabra que comienza con el fonema /s/ o una consonante fricativa. De hecho, la mayoría de las fuentes que hablan sobre este rasgo presentan un grupo reducido de ejemplos que, en algunos casos, se trata de las únicas palabras que se encontraron con jejeo. De entre todos los vocablos es el pronombre personal de sujeto nosotros el que se menciona con mayor frecuencia en todas las variedades jejeístas del español.

Muchas de las variedades del español que aspiran otras consonantes fricativas a inicio de palabra o de sílaba son, además, variedades jejeístas. Por ejemplo, en Nicaragua, Mántica (1997) transcribió ortográficamente la pronunciación de ciertas palabras que comenzaban con $\mathrm{F}$ o H por J para el habla de dos informantes nicaragüenses: Jue para fue, julano para fulano, juida para huida, jueron para fueron, juí para fui. Todos estos ejemplos carecían de una terminología precisa que los definiese y la única diferencia que guardan respecto a ejemplos de palabras con jejeo es la consonante inicial que se aspira, lo que pudiese indicar que no es arbitrario el que todos estos vocablos comiencen por una consonante fricativa. La nueva definición del jejeo propuesta por Rodríguez (2008) abraza todos aquellos vocablos que se pronuncian con aspiración cuando tienen cualquier consonante fricativa a inicio de palabra o de sílaba.

En español se suele valorar de manera positiva el que haya una correspondencia entre la pronunciación y la escritura. El jejeo supone una ruptura de esta correspondencia y la situación empeora ya que dicho proceso no aplica de manera consistente. Pero desde un punto de vista puramente formal, el estigma hacia el uso del jejeo no está justificado. De hecho, no todas las eses finales de palabra o de sílaba se pronuncian en posición postnuclear dentro de la cadena hablada. En el sintagma nominal los otros, ambas palabras terminan en S y se considera que la sílaba final de cada palabra tiene el fonema/s/ en posición de coda. Pero eso es cierto en la ortografía solamente ya que dicho sintagma se pronunciaría [lo.'ho.troh] y no [loh.'o.troh], a menos que se tratase de una pronunciación enfática. Lo importante del caso es que se percibe la pronunciación jejeísta del pronombre de sujeto nosotros [no.'ho.troh] como vulgar y estigmatizada pero, por otro lado, se percibe como aceptable y natural la pronunciación de los otros con aspiración en los dos fonemas /s/ implosivos [lo.'ho. troh]. Si contrastamos los dos ejemplos anteriores se puede ver que en realidad se trata de un par mínimo en el que solamente una de las dos opciones está estigmatizada. Es posible entonces que la falta de sistematicidad con la que se aplica este fenómeno lingüístico del jejeo sea lo que propicia el valor negativo y el estigma hacia esta aspiración frente a otras aspiraciones similares que se producen en muchas variedades del español.

\section{El jejeo en América Central}

El jejeo es un proceso de simplificación, y toda simplificación se debe a la tendencia al menor esfuerzo. Rosenblat (2002) mencionó que en todos los países hispanohablantes de las tierras bajas, es decir, las regiones costeras y las islas, se manifiesta una tendencia al relajamiento en la articulación de la letra S. De hecho, Rosenblat (2002) opinó que este rasgo lingüístico es el más importante en la división entre tierras bajas y altas en Latinoamérica. En muchas regiones de las tierras bajas la aspiración de la letra S Ilega a afectar a la /s/ intervocálica y a la inicial de sílaba dentro de la cadena hablada, y no solamente a la inicial de palabra. Como buenos ejemplos de tierras bajas, en esta sección se describen las regiones de América Central donde se puede encontrar el fenómeno del jejeo, entendido como la sustitución esporádica y léxicamente condicionada de cualquier consonante fricativa por [h] a principio de sílaba o de palabra. Más específicamente, Frago y Franco (2003) mencio- 
naron El Salvador, Costa Rica y Nicaragua como países centroamericanos que aspiran la /s/ en posición prenuclear tanto al inicio como en el interior de palabra: [la.ha.'ba.na], la sabana; [la. ko.'hi.na], la cocina; [no.'ho.tro], nosotros. En el mapa 1 se muestra de manera simplificada la situación del jejeo en América Central teniendo en cuenta todas las consonantes fricativas. Y en los siguientes párrafos se describe en más detalle la situación de este fenómeno en cada país centroamericano en particular.

\section{MAPA 1}

Distribución geográfica del jejeo en Centroamérica

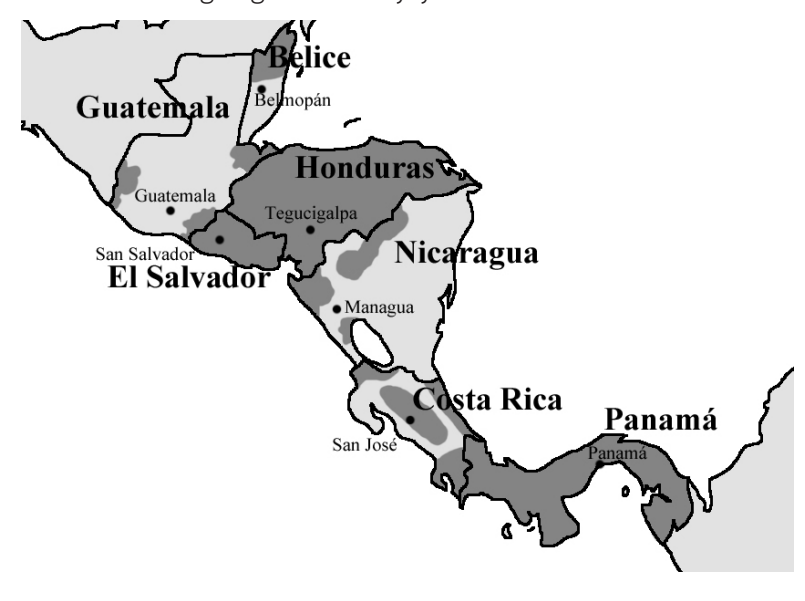

Para Belice, Cardona (2010b) encontró algunos ejemplos de palabras con jejeo para la fricativa labiodental a inicio de palabra, sobre todo en las zonas más rurales del norte. En los ejemplos de los 39 encuestados, encontró /f/ como [h] en foto (1/39, 2.5\%), fútbol (1/39, 2.5\%) y fuerte ['hwuer.te] (3/39, 7.6\%)

En Guatemala se han constatado ejemplos de jejeo para los fonemas fricativos /f/, /s/ y /x/, aunque siempre de manera puntual. Alvar (1980) encontró que algunos de sus informantes aspiraron /f/ en palabras como fue, fuente, fulano y difunto. Utgård (2010) también encontró el alófono [h] para /f/ ante el diptongo creciente /we/ como en fuerte en escasas ocasiones (en el 3.4\% de los ejemplos) y particularmente en los hombres mayores de Livingston, Ocós y Jutiapa. De entre sus 88 informantes, Utgård (2010) encontró a un joven de Ocós (que hace frontera con México, en el occidente del país) aspirando la /s/ inicial en ejemplos como: podría ser [po.'dri.a.'her]

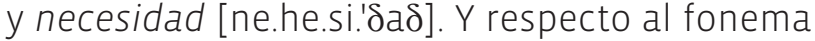
/ $\mathrm{X} /$, en la zona oriental y en la caribeña tan solo el $3.6 \%$ de los informantes alteraron entre $[\mathrm{x}]$ y $[\mathrm{h}]$, mientras que la presencia de [h] fue muy poco común, con una media del $4.7 \%$ en los datos de Utgård (2010).

Honduras es el país centroamericano del que más información se tiene sobre el jejeo, gracias a los estudios realizados por Lipski en los años 1987, 1990 y 2002. En general, las tasas de reducción de /s/ en posición inicial de palabra son menores que las de final de palabra. Pero se reconoce que se trata de un proceso de cierta envergadura que no se debe al azar. De hecho, Lipski (1987) mencionó que perfectamente se le puede considerar un proceso sistemático en el español hondureño por sus altas tasas de aplicación. En muchas zonas del país la/s/inicial de palabra se reduce a [h] en posición intervocálica en el habla continua, por ejemplo: la semana [la. he.'ma.na] (Lipski, 2002). También se debilita la/s/ intervocálica interior de palabra pero en menor grado, como en presidente [pre.hi.'Sen.te] y licenciado [li.hen.'sja.do]. Los ejemplos que Lipski (1987) encontró le hicieron pensar que este tipo de jejeo ocurre solamente entre morfemas (pre+supuesto, des+empleo) o en palabras que pareciesen tener una estructura bimorfémica (de-cisión, pre-sidente). También mencionó que la secuencia de dos eses favorece la aspiración inicial de sílaba interior de palabra, por un proceso de disimilación. Recordemos que la disimilación consiste en diferenciar sonidos iguales o parecidos dentro de un mismo vocablo: licenciado [li.

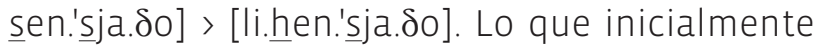
pudiese haber surgido en un grupo reducido de vocablos parece haberse extendido a un campo léxico más amplio. Lipski (1987, 1990) mencionó que los términos que con mayor frecuencia se escuchan con jejeo tanto en Honduras como en 
El Salvador son centavos en combinaciones con otros numerales tales como cincuenta, sesenta, setenta, etc. En su base de datos sobre el habla de Tegucigalpa de 80 entrevistas a hablantes de tres categorías en base a su nivel de escolaridad (poco o nada, nivel de secundaria y nivel universitario), Lipski (1987: 113) enumeró las siguientes palabras en las que el jejeo era más frecuente: se (11.7\%), centavo (10\%), situación (9\%), cincuenta $(4.7 \%)$, sesenta (4.6\%), setenta (5\%), San Pedro (Sula) (4.5\%), central (4.1\%), señor/señora (3.6\%) y semana (2.5\%). Según Lipski (2002), parece que para muchos hablantes estas palabras se han lexicalizado con una [h] inicial, de tal modo que un centavo puede pronunciarse con [h] inicial de palabra. La secuencia de fonemas en la que el jejeo suele aparecer con mayor frecuencia es [VhV] independientemente de dónde ocurra la división entre palabras, es decir, la posición del límite de palabra no necesita ser especificada con precisión: Vh\#V (/s/ prevocálica final de palabra) o V\#hV (/s/ postvocálica inicial de palabra). El jejeo hondureño refleja de manera más directa la marginación sociolingüística pues este rasgo lingüístico predomina entre las clases trabajadoras y los habitantes rurales. Y es que Lipski (2002) mencionó que es inusual en el nivel más coloquial del habla de los hondureños cultos, o en el habla autoconsciente y cuidada, en la lectura o en el habla en público. Por el contrario, el trabajo de Hernández (2010) no cuenta con datos significativos para el jejeo hondureño, ni para/s/ ni para/f/. Más concretamente, en posición postnuclear ante vocal, tan solo 5 de 84 informantes (el 5.95\%) aspiraron/s/, mientras que para/f/solo pudo constatar dos ejemplos aspirados (2.38\%) de fútbol y uno (1.19\%) de afuera. Tampoco fue significativa la presencia del alófono glotal [h] para /X/ en los datos de Hernández (2010): tan solo en el $11.11 \%$ de los informantes en el Departamento de Colón, en el $\mathbf{1 2 . 5 \%}$ de los de Atlántida y en el 30\% de los de Islas de Bahía.

Para El Salvador, Henríquez (2001) señaló de forma general que una de las características del español de dicho país es la aspiración de /s/ implosiva, mientras que Lipski (2000) mencionó que el jejeo para/s/ interior intervocálica e inicial se encuentra en todos los niveles socioculturales. En el trabajo de Azcúnaga (2010), si bien los datos de los 80 informantes no registraron de manera sistemática la aspiración de /s/ inicial, esta sí se encontró a inicio de sílaba en palabras como: salud [ha.'lu], entonces [en.'ton.he], de Santa Ana [de.han,.ta.na], la Sandrita [la.han,.'dri.ta], etc. En el caso de la /s/ prevocálica y final de palabra como en los ojos, Azcúnaga (2010) encontró el alófono aspirado [h] en el $26.3 \%$ de los datos $(21 / 80)$ al igual que evidencia de alternancia [s] [h] en el $6.2 \%$ de los datos (5/80). Su análisis dialectal visualizó la zona del centro del país como más proclive al alófono dorsoalveolar [s] mientras que la mayor variación alofónica para /s/ se encontró en las provincias periféricas. Lipski (2002) destacó la reducción omnipresente de /s/ a [h] en el adverbio entonjes y mencionó que el español salvadoreño también reduce a [h] la /s/ postconsonántica inicial de palabra en combinaciones como El Jalvador y un jentavo. Canfield (1981) mencionó como ejemplo de "jejeo" salvadoreño el nombre de uno de sus departamentos: ['han.ta.'a.na] Santa Ana. Geoffroy (1975) propuso la hipótesis de que los ejemplos de jejeo salvadoreño son una consecuencia directa del habla de los indígenas náhuatl que comenzaron a hablar español una vez establecida la Colonia. Estos indígenas aprendieron a hablar español a través del contacto diario con los invasores y no por medio de la enseñanza gramatical en las escuelas. Como consecuencia directa de esta situación de lenguas en contacto, se produjo lo que el autor denomina como la "deformación" de las palabras españolas al suprimir toda diferencia entre las grafías S, C y Z siendo sustituidas por el fonema náhuatl velar fricativo sordo que suena como una jota suave: nojotros. Según Geoffroy (1975), este sonido es más notorio y perceptible 
por los hablantes salvadoreños en el habla de los nicaragüenses. En referencia a la fricativa /f/ y citando ejemplos en los libros de Sabino Deodanes, Romero (2003) mencionó que las letras F y H se aspiran en el español salvadoreño por influencia de los hábitos lingüísticos náhuatles sobre la lengua española: [ku.hrwa.'di.ya] cofradía, [a.'hwan] afán, [ha.'si.ya] hacía, [hu.'yi.tu] ho-

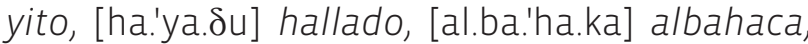
['ha.ča] hacha. Lipski (2000) también afirma que la realización de /f/ como [h] ante la vocal/u/, la semivocal /w/ y algunos grupos consonánticos como /fl/ puede relacionarse con una posible etapa prolongada de bilingüismo en zonas de fuerte presencia indígena. Y el trabajo de Azcúnaga (2010) ofrece ejemplos de /f/ glotal [h] en posición interna de palabra al contacto con /s/ como en fósforo (2/80, $2.5 \%)$, ante diptongo creciente como en afuera (13/80, $16.2 \%)$ y en posición inicial ante /u/ como en fútbol (5/80, 6.2\%). Por último, y haciendo referencia al fonema fricativo velar sordo /X/, ya Canfield (1960) y González (1963) coincidieron en que este fonema se confunde con la jota, la F ante UE y la S aspirada, lo que lleva a casos de neutralización entre / $\mathrm{X}$, /f/ y la antigua /h/: jedentina, jue, dijunto.

En Nicaragua parece que hay evidencia de jejeo para las fricativas /f/ y /s/, en base a los datos de Rosales (2010). En toda la región Central y Pacífica (Chinandega, León, Masaya y Granada, a excepción de Managua y Rivas), en el 16\% de las ocasiones se escucha la variante aspirada [h] de /f/ ante el diptongo /we/ como en afuera [a.'hwe. ra]. Lo más interesante del caso es que la autora constató que varios informantes, que habían pronunciado [f] en el cuestionario, pronunciaron fuego como ['hwe.yo] durante la conversación libre. Respecto a la /s/, se encontró un ejemplo de jejeo a inicio de palabra (sacar [ha.'kar]) en Jinotega, en la zona norte del país, mientras que en posición postnuclear ante vocal (Ios ojos [lo.'ho.hoh]) tuvo una escasa incidencia, solo en la región centro-norte.
El caso de Costa Rica se menciona en Alvar (1996), donde se recoge que el jejeo se encuentra en la región central del país en el habla rápida y descuidada, principalmente en casos de disimilación, como ya vimos en el caso de Honduras. En el presente fenómeno del jejeo costarricense, la disimilación ocurre cuando hay dos eses dentro de la misma palabra. El ejemplo que mencionaron fue: [ne.se.'sa.rjo] > [ne.he.'sa.rjo] necesario. Quesada y Vargas (2010) encontraron que, de entre sus 144 informantes, algunos (36/144, el $25 \%$ aspiraron /s/ en posición postnuclear ante vocal en ejemplos como los ojos, mientras que otros tantos (22/144, el 15.2\%) alternaron su pronunciación entre la realización alveolar [s] y la aspirada [h]. La zona noroeste a lo largo de la frontera con Nicaragua y la zona sur hacia la frontera con Panamá es donde se registraron los mayores índices de estas aspiraciones. En el caso de la fricativa /f/, tanto Agüero (2009) como Quesada y Vargas (2010) encontraron ejemplos de /f/ aspirado como la jota costarricense principalmente cuando aparece delante de /u/, /we/ o /wi/. Algunos de los ejemplos que ofrece Agüero (2009) incluyen: perjume (perfume), juerza (fuerza) y jui (fui), mientras que el trabajo de Quesada y Vargas (2010) indica que fútbol y afuera se escucharon con el alófono glotal [h] por el $12.5 \%$ y el $20.1 \%$ de sus informantes, respectivamente. Por último, y en referencia al fonema /X/, Quesada y Vargas (2010) encontraron porcentajes altos de pronunciación faríngea o laríngea cuando aparece en contacto con las vocales posteriores y sobre todo en la región noroeste, en el litoral atlántico y en el Pacífico sur: en el $47.9 \%$ de sus informantes (69/144) ante /o/ como en abajo y en el 36.8\% (53/144) ante /u/ como en junio.

En Panamá, Cardona (2010a) no encontró evidencia de jejeo para la fricativa alveolar /s/ prenuclear $y$, de entre todos los contextos postnucleares posibles, es precisamente ante vocal la que obtuvo el mayor porcentaje de pronunciación plena (para 64 de los 76 informantes, o el $86.5 \%$ ). Solamente hubo un caso de pronuncia- 
ción glotal sorda (1.4\%) y otro de glotal sonora (1.4\%) para el ejemplo Estados Unidos. Respecto al fonema /f/, a lo largo de todo el país (desde la provincia de Chiquirí hasta la provincia del Darién) y sobre todo en las zonas rurales, se encontraron casos de velarización con alternancias entre $[x]$ y [h] principalmente ante /u/. Más concretamente, Cardona (2010a) encontró: nueve realizaciones aspiradas (11.8\%) ante la /u/ como en fútbol [hut.'bol], cinco (6.6\%) ante [we] como en fuerte ['hwer.te]; otras cinco (6.6\%) ante la lateral /// como en flor ['hlor] y tres (4\%) ante /o/ como en foto ['ho.to].

La importancia de muchos de los ejemplos mencionados reside, de nuevo, en el hecho de que no sería posible identificarlos con un término lingüístico preciso a menos que se acepte la nueva definición de jejeo propuesta por Rodríguez (2008).

\section{Ejemplos de la nueva definición de jejeo en el español salvadoreño}

Dado que el jejeo es un fenómeno que se aplica de manera inconsistente a cierto número de vocablos y que está estigmatizado, supone un gran desafío el poder recoger datos espontáneos para estudiar este fenómeno en mayor detalle. No obstante, el presente estudio pretende ofrecer algunos ejemplos del jejeo en el español salvadoreño para determinar si la reformulación de la definición de este fenómeno propuesta por Rodríguez (2008) pudiese ser validada o si bien se trata de una extensión innecesaria de escasa aplicación. A continuación se describen las dos fuentes, una oral y otra escrita, que se usaron para ofrecer ejemplos del jejeo en El Salvador.

\subsection{Ejemplos orales de jejeo en el español salvadoreño}

La fuente oral es una grabación de voz realizada durante un viaje que realicé a San Salvador. En un intento de obtener ejemplos completamente espontáneos, coloqué una videocámara encima de una mesa mientras mantenía una conversación informal y distendida con una ha- blante salvadoreña de más de 60 años a la que acababa de conocer hacía escasos momentos. La interlocutora no fue informada de la grabación hasta que la cinta de video llegó a su fin, momento en el que se le informó de la grabación y en el cual ella dio su pleno consentimiento de ser utilizada con fines lingüísticos. En ningún momento se forzó ningún tema ni se le pidió que pronunciara o repitiera ninguna oración para forzar los ejemplos que se presentan a continuación. La interlocutora tampoco se percató de la grabación ya que la grabación se realizó con el lente de la cámara cubierto para disipar cualquier sospecha y evitar un posible ruido sospechoso del motor del enfoque automático del lente. En resumen, la conversación tuvo lugar de manera natural y espontánea en un ambiente distendido entre una hablante salvadoreña y un recién llegado al país. En la tabla 1 se muestran los únicos cuatro vocablos que se encontraron en la grabación de voz de unos 50 minutos de duración.

\section{TABLA 1}

Ejemplos de jejeo en una grabación de voz a una informante salvadoreña

\begin{tabular}{c|c|c}
$\begin{array}{c}\text { Fonema } \\
\text { aspirado }\end{array}$ & Posición & \multicolumn{1}{c}{ Ejemplo literal } \\
\hline \multirow{5}{*}{$/ \mathrm{s} /$} & $\begin{array}{c}\text { Ainicio } \\
\text { de } \\
\text { palabra } \\
\text { que siempre viene a dejar. } \\
\text { Ahí abajo, la señora [he.'ño.ra] } \\
\text { de ahí abajo tiene un palo de } \\
\text { guanaba. } \\
\text { Tal vez la otra semana [he.'ma. } \\
\text { na] van pa' que vaya a conocer } \\
\text { la casa. }\end{array}$ \\
\cline { 2 - 3 } & $\begin{array}{l}\text { A inicio } \\
\text { de sílaba }\end{array}$ & $\begin{array}{l}\text { Yentonces ese [jen.'to.he.he.se] } \\
\text { día nos dieron el cheque. }\end{array}$
\end{tabular}

Como era de esperar, el número de palabras pronunciadas con jejeo fue muy escaso ya que la grabación de video era de corta duración y porque no se realizó teniendo en cuenta el presente análisis de antemano. Desafortunadamente, en esta recogida de datos no se encontraron ejemplos de jejeo que justifiquen una necesidad para la nueva definición del jejeo, ya que en todos los ejemplos el único fonema que se aspira es la con- 
sonante /s/ a inicio de palabra en la mayoría de los casos. No obstante, exactamente lo opuesto es lo que ocurrió con los ejemplos encontrados en la fuente escrita que a continuación pasamos a analizar en detalle.

\subsection{Ejemplos de jejeo en la obra Cuentos de barro de Salarrué}

La fuente escrita para este estudio es el libro Cuentos de barro, escrito por el autor salvadoreño Salvador Salazar Arrué (1899-1975), mejor conocido por el seudónimo Salarrué. Las historias que se narran en el libro son un acercamiento a la realidad de los campesinos salvadoreños y a su peculiar manera de ver el mundo. Las historias son sencillas en la forma pero profundas y conmovedoras, en las que se contrasta la carencia de una educación formal de los personajes con su sabiduría ancestral. En la edición del año 2000 de la editorial Legado se dice que en este libro "Salarrué penetra en la psicología de los personajes y sus variados ambientes, hasta lograr una visión panorámica de la realidad salvadoreña”. Y para poder reflejar esa realidad salvadoreña de manera creíble, el autor se esforzó en plasmar de manera fidedigna el habla típica de los campesi- nos salvadoreños, tras una observación cuidadosa del habla espontánea salvadoreña o incluso quizás a través de la introspección de su propia experiencia con dichos hablantes.

Dado que Salarrué escribió estas historias siguiendo la fonética propia de sus personajes campesinos y de su léxico, aquellos lectores que no son salvadoreños van a tener dificultades con algunas palabras. El autor plasmó la realidad del mundo rural salvadoreño a través de la escritura, utilizando un lenguaje que refleja de manera fiel el habla real de sus personajes, aunque eso conlleva la violación de muchas de las reglas prescriptivas y correctivas del español estándar. Por ejemplo, se escribe ¿diondés? en vez de "¿de dónde es?”, o ¡No siás cobija, vos; ya no te güelvo a trer! para "iNo seas cobija (miedosa), vos; ya no te vuelvo a traer!". En la propia edición de la editorial Legado (2000) se incluye un glosario con los modismos usados por el autor para facilitarle la lectura al lector que no sea salvadoreño.

Al basar sus escritos en la pronunciación característica de los campesinos salvadoreños, Salarrué escribió muchas palabras con jejeo, ya fuese de manera consciente o inconscien-

\section{TABLA 2}

Clasificación de los ejemplos de jejeo en la obra Cuentos de barro en base al fonema aspirado y su posición en la palabra

\begin{tabular}{|c|c|c|}
\hline $\begin{array}{l}\text { Fonema } \\
\text { aspirado }\end{array}$ & Posición & Ejemplo literal (páginas en el libro) \\
\hline /s/ & $\begin{array}{c}\text { A inicio de sílaba } \\
\text { 1/113 }(0.88 \%)\end{array}$ & peje "singular de peces" (28) \\
\hline \multirow[t]{2}{*}{$/ f /$} & $\begin{array}{l}\text { A inicio de } \\
\text { palabra } \\
58 / 113(51.33 \%)\end{array}$ & 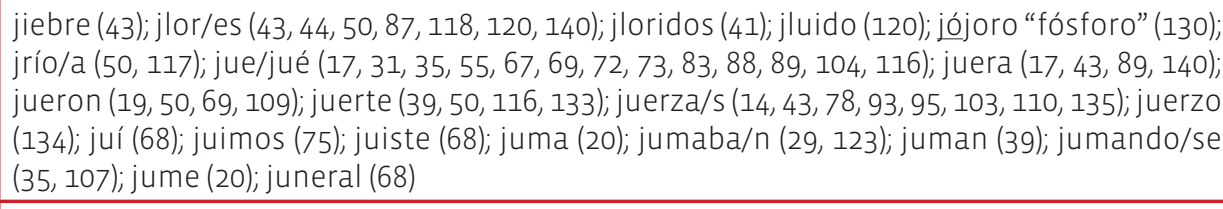 \\
\hline & $\begin{array}{l}\text { A inicio de sílaba } \\
26 / 113(23.01 \%)\end{array}$ & $\begin{array}{l}\text { ajuera (109); aljiler (136, 137); aljombra (108); conjormaban (109); conjundir (43); dijunto/a/s } \\
\text { (23, 74, 75, 88, 89); injiernos (110); jójoro "fósforo" (130); ojicio (117); ojreció (86); parajuera } \\
\text { (75); perjumaba (19); perjumándolo (67); perjume (43); projundo/a/s (14, 43, 116, 127, 128); } \\
\text { tujito (108); tujo (116) }\end{array}$ \\
\hline \multirow{2}{*}{$\begin{array}{c}\text { / / (letra } \\
\text { "h") }\end{array}$} & $\begin{array}{l}\text { A inicio de } \\
\text { palabra } \\
27 / 113(23.89 \%)\end{array}$ & $\begin{array}{l}\text { jaz (41, 42, 135); jedía (117, 136); jediondo (25, 62, 115); jelado/a (45, 61); jiede (89); jierro (13, } \\
\text { 104); jondo (115, 116, 117); juelgo (107, 115); juido/juído }(36,44,94,98) \text {; julunera "huronera = } \\
\text { lugar oscuro y extraviado" (33, 87); jumazón (91, 112); jumo }(46)\end{array}$ \\
\hline & $\begin{array}{c}\text { A inicio de sílaba } \\
\text { 1/113 (0.88\%) }\end{array}$ & albajaca (134) \\
\hline
\end{tabular}


te. Es por ello que esta fuente es de gran valor lingüístico para el presente análisis sirviendo, además, como una herramienta clave para identificar ejemplos de la nueva definición del jejeo propuesta por Rodríguez (2008). En la tabla 2 se muestran todos los ejemplos con aspiración de fonemas fricativos a inicio de palabra o de sílaba. Salarrué marcó estas aspiraciones con la grafía J probablemente con la intención de resaltar y hasta exagerar dicho fenómeno dialectal.

No resulta difícil observar que prácticamente todos los ejemplos de palabras con jejeo encontrados no hubiesen sido considerados como tal ya que la aspiración, pese a ser esporádica y léxicamente condicionada, no se produce con el fonema /s/. Solamente hay un ejemplo de jejeo a inicio de sílaba con el fonema/s/: peje, como si fuera el singular de peces. Casi las tres cuartas partes de todos los ejemplos de jejeo se producen con el fonema / $f$ /, bien sea a inicio de palabra, como en juerte para fuerte, o bien a inicio de sílaba interior de palabra, como en dijunto para difunto. Y casi una cuarta parte de los ejemplos de jejeo pertenecen a palabras con la grafía $\mathrm{H}$ a inicio de palabra. En estos casos, la consonante debiera ser sorda excepto en los casos en los que aparece con un diptongo creciente del tipo HIEya que en la mayoría de las variedades del español se pronuncia como palatal fricativa sonora o, lo que es lo mismo, /ye-/.

Recordemos que una de las características del fenómeno del jejeo es que la aspiración es esporádica y que no aplica de manera consistente. A lo largo del libro, se puede observar que el autor no emplea la aspiración de los fonemas mencionados cada vez que aparecen las palabras incluidas en la tabla 2. Algunos ejemplos que se pueden mencionar para ilustrar la inconsistencia en su aplicación son: flor (71), fue (25), fueron (35), haz (69), hediondo (42), hierro (58), profundo (80), etc. Es decir, mientras en la página 25 se escribe la forma verbal fue sin aspiración (Se apió y, remangándose la sotana, fue al platanar con Ulalio, la Chana y Julián), en la página 31 la mis- ma forma verbal aparece con jejeo (A saber si jué Mincho de la señá Fabiana). Lo mismo ocurre con los sustantivos, como es el caso de la palabra flor, que aparece sin aspiración en la página 49 (en el margen, vagos ruidos de bocas que se abren a flor de agua) y con aspiración en la página siguiente (era como el corazón amariyo de una jlor algodonosa), a escasas líneas del ejemplo anterior. Y también aplica para los adjetivos, como por ejemplo hediondo, con aspiración en la página 62 (Daba la impresión de bañada, dentro del traje pushco y jediondo) y sin aspiración en la página 42 (Arrojaba un piro espumosos y hediondo y diay se desmayaba).

Del mismo modo, se observa que el jejeo está léxicamente condicionado a un grupo bastante limitado de vocablos, a tan solamente unas 50 palabras. Se pueden encontrar literalmente cientos de palabras que bien comienzan por consonantes fricativas o bien contienen sílabas que comienzan con consonantes fricativas sin que ninguna de ellas sufra aspiración a lo largo de todo el texto.

En resumen, y en base a los datos presentados en la tabla 2, se puede concluir que Salarrué realizó un excelente trabajo en su obra Cuentos de barro a la hora de reflejar el habla rural salvadoreña en sus personajes. Y eso incluye el plasmar el jejeo en todo su esplendor, como proceso de aplicación inconsistente y que está relegado a un reducido número de vocablos.

Este estudio demuestra que la nueva definición del jejeo propuesta por Rodríguez (2008) ayuda a explicar algunos fenómenos en el español que hasta entonces no tenían una manera precisa de ser identificados. Recordemos que unas tres cuartas partes de los fonemas aspirados a inicio de sílaba o palabra en Cuentos de barro fueron con la consonante /f/ y no con la /s/. Del mismo modo se puede concluir que quizás no todas las consonantes fricativas del español tienden a aspirarse de manera inconsistente en variedades jejeístas. Por ejemplo, no se han encontrado en este estudio ejemplos de jejeo con 
la consonante fricativa palatal sorda /y/ ni tampoco en ninguno de los países centroamericanos en base a la revisión de las fuentes usadas en este trabajo. Futuros estudios podrían indagar sobre este aspecto para determinar cuáles son los fonemas consonánticos del español que realmente sufren el fenómeno del jejeo y, de esta manera, poder delimitar mejor una categoría tan abierta como es la de las consonantes fricativas. A falta de más datos en el habla espontánea, se sugiere que futuras investigaciones tomen en cuenta no solo el habla informal de diferentes grupos de participantes en base a su nivel de instrucción (elemental, bachillerato, universitario) y núcleo de población (rural, urbano), sino también en base a su edad (jóvenes, adultos y ancianos). De esta manera, se podría determinar si el fenómeno del jejeo pudiera ser un rasgo estable entre diferentes generaciones de informantes o si bien se puede considerar un rasgo bien en desuso o bien de empleo continuado. Cabe mencionar, no obstante, lo difícil que puede resultar dicha recogida de datos, ya que, como se ha insistido en este estudio, se trata de un fenómeno condicionado léxicamente y que no aplica de manera consistente.

\section{Conclusión}

El jejeo es un rasgo lingüístico característico de muchas variedades del mundo hispanohablante pero que está estigmatizado por ser un fenómeno de aplicación inconsistente además de ser empleado mayoritariamente por hablantes de los estratos sociales más bajos y en el habla informal. El incorporar en la definición de este fenómeno dialectal todas las consonantes fricativas que sufren un proceso de relajación articulatoria, condicionado léxicamente a inicio de palabra o de sílaba, ayuda a comprender mejor un rasgo lingüístico tan extendido al igual que tan estigmatizado. Al emplear en este estudio la nueva definición del jejeo, que incluye todas las consonantes fricativas, se han podido ofrecer muchos ejemplos del jejeo en Centroamérica y más concretamente en El Salvador que, de otra manera, hubiesen quedado a la espera de una terminología precisa que los definiese. Por otro lado, el presente análisis sugiere que la renovada definición del jejeo es demasiado amplia y que una revisión del subgrupo de consonantes fricativas que realmente se aspiran podría ser más precisa.

\section{Bibliografía citada}

Agüero, Arturo, 2009: El español de Costa Rica, San José: Universidad de Costa Rica.

Alvar, Manuel, 1980: "Encuestas fonéticas en el suroccidente de Guatemala", Lingüística Española Actual 2, 245-298.

Alvar, Manuel, 1996: Manual de dialectología hispánica: El español de América, Barcelona: Editorial Ariel.

Azcúnaga López, Raúl Ernesto, 2010: "Fonética del español salvadoreño" en Miguel Ángel QuesadA PACHeco (ed.): El español hablado en América Central. Nivel fonético, Madrid: Iberoamericana Vervuert, 83-113

Canfield, Delos Lincoln, 1960: "Observaciones sobre el español salvadoreño”, Filología 6, 29-76. Canfield, Delos Lincoln, 1981: Spanish pronunciation in the Americas, Chicago: University of Chicago Press.

Cardona Ramírez, Mauricio Andrés, 2010a: "Fonética del español de Panamá” en Miguel Ángel QueSADA PACheco (ed.): El español hablado en América Central. Nivel fonético, Madrid: Iberoamericana Vervuert, 177-210.

Cardona Ramirez, Mauricio Andrés, 2010b: "La fonética del español en Belice” en Miguel Ángel QueSADA PACHECo (ed.): El español hablado en América Central. Nivel fonético, Madrid: Iberoamericana Vervuert, 21-48.

Frago Gracia, Juan Antonio y Mariano Franco FigueROA, 2003: El español de América, Cádiz: Servicio de Publicaciones de la Universidad de Cádiz.

Geoffroy Rivas, Pedro, 1975: La lengua salvadore- 
ña: El español que hablamos en El Salvador, San Salvador: Ministerio de Educación.

González Rodas, Publio, 1963: Jaraguá, una novela salvadoreña. Estudio fonológico, San Salvador: Editorial Universitaria.

Henriquez, José, 2001: "Observaciones generales del español en El Salvador”, CIL: Antología Lingüística 9, 29-48.

Hernández Torres, Ramón Augusto, 2010: "Fonética del español de Honduras" en Miguel Ángel Quesada PAcheco (ed.): El español hablado en América Central. Nivel fonético, Madrid: Iberoamericana Vervuert, 115-136.

LIPSKI, John, 1987: Fonética y fonología del español de Honduras, Tegucigalpa: Editorial Guaymuras. LIPSKI, John, 1990: "Reducción de la /s/ en el español de Honduras" en Atanasio Herranz (ed.): El español hablado en Honduras, Tegucigalpa: Editorial Guaymuras, 91-110.

LIPSKI, John, 2000: "El español que se habla en El Salvador y su importancia para la dialectología hispanoamericana", Científica 2:1, 65-88.

LIPskı, John, 2002: El español de América, Madrid: Cátedra.

Mántica, Carlos, 1997: Introducción al habla nicaragüense, Managua: Editorial Hispamer.

Narbona, Antonio, Rafael Cano y Ramón Morillo, 2003: El español hablado en Andalucía, Sevilla: Fundación José Manuel Lara.

Quesada Pacheco, Miguel Ángel y Luis Vargas VarGAS, 2010: "Rasgos fonéticos del español de Costa Rica" en Miguel Ángel Quesada Pacheco (ed.): El español hablado en América Central. Nivel fonético, Madrid: Iberoamericana Vervuert, 155-175.

Rodriguez Prieto, Juan Pablo, 2008: "Distribución geográfica del 'jejeo' y propuesta de reformulación y extensión del término", Revista Española de Lingüística 38.2, 129-144.
Romero, Matías, 2003: Diccionario de salvadoreñismos, Santa Tecla: Editorial Delgado.

Rosales Solís, María Auxiliadora, 2010: “El español de Nicaragua” en Miguel Ángel Quesada PACHeco (ed.): El español hablado en América Central. Nivel fonético, Madrid: Iberoamericana Vervuert, 137-154.

Rosenblat, Ángel, 2002: El español de América, Caracas: Biblioteca Ayacucho.

Salazar Arrué, Salvador, 2000: Cuentos de barro, San Salvador: Editorial Legado.

Schwegler, Armin, 1991: "El habla cotidiana del Chocó (Colombia)", América Negra 2, 85-119.

UtGÅRD, Katrine, 2010: "El español de Guatemala" en Miguel Ángel Quesada Pacheco (ed.): El español hablado en América Central. Nivel fonético, Madrid: Iberoamericana Vervuert, 49-81. 